\title{
Qualidade no Ensino a Distância: um conceito polissêmico
}

\author{
Quality in Distance Education: a polysemic concept \\ Calidad en la Educación a Distancia: un concepto polisémico
}

Recebido: 22/09/2021 | Revisado: 28/09/2021 | Aceito: 01/10/2021 | Publicado: 03/10/2021

\author{
Alequexandre Galvez de Andrade \\ ORCID: https://orcid.org/0000-0002-5847-7616 \\ Instituto Federal de São Paulo, Brasil \\ E-mail: aleq.galvez@ifsp.edu.br \\ Elaine Santos Ferreira \\ ORCID: https://orcid.org/0000-0003-4776-4895 \\ Universidad Columbia del Paraguay, Paraguai \\ E-mail: es.ferreiraelaine@gmail.com \\ Lana Cristina de Almeida Silva \\ ORCID: https://orcid.org/0000-0003-1391-5034 \\ Universidad Columbia del Paraguay, Paraguai \\ E-mail: lanamestranda@gmail.com \\ Thatiana Soares dos Santos \\ ORCID: https://orcid.org/0000-0001-5217-3462 \\ Universidad Columbia del Paraguay, Paraguai \\ E-mail: thatianasoaresdossantos@gmail.com \\ Nélio Fernando dos Reis \\ ORCID: https://orcid.org/0000-0002-1694-4917 \\ Instituto Federal de São Paulo, Brasil \\ E-mail: nelio.reis@ifsp.edu.br
}

\begin{abstract}
Resumo
O ensino a distância (EAD) na educação superior tem crescido substancialmente no Brasil, para alguns trata-se de uma modalidade e para outros uma nova pedagogia com um novo campo de estudo, principalmente na educação de adultos. Este impulso do ensino a distância é marcado pelo crescimento tanto em instituições como de alunos por meio da ampliação de cursos e polos de apoio, democratizando o ensino. Desta forma, um aspecto que tem sido discutido e disputado no EAD é a qualidade, estudos demonstram que há equivalência na qualidade entre ensino presencial e a distância quando considerado as notas das avaliações para o ensino superior. O objetivo deste estudo foi identificar quais fatores estão ligados a qualidade no ensino a distância. Para isto, foi realizada uma análise bibliográfica seguindo procedimentos de seleção quanto a citação e análise dos especialistas para listar os artigos a serem avaliados, após este filtro selecionou-se a conclusão destes artigos e aplicou a análise de conteúdo por meio do uso do software Iramuteq. Os resultados indicam que a qualidade é um conceito polissêmico e esta relacionada a gestão, engajamento da equipe, corpo docente, corpo discente, avaliações institucionais, legislação, infraestrutura, gestão, tecnologias e suas aplicações.
\end{abstract}

Palavras-chave: Ensino a distância; Qualidade no ensino a distância; Análise CHD; Análise de similitude.

\begin{abstract}
Distance learning in higher education has grown substantially in Brazil, for some it is a modality and for others a new pedagogy with a new field of study, especially in adult education. This boost in Distance Education is marked by the growth in both institutions and students through the expansion of courses and support centers, democratizing education. In this away, one aspect that has been discussed and disputed in distance education is quality. Studies show that there is equivalence in quality between classroom teaching and e-learning when considering the grades of the evaluations for higher education. The aim of this study was to identify which factors are linked to quality in distance education. For this, a bibliographic analysis was performed following selection procedures regarding citation and expert analysis to list the articles to be evaluated. After this filter, the conclusion of these articles was selected and content analysis was applied using the Iramuteq software. The results indicate that quality is a polysemic concept and is related to management, team engagement, faculty, student body, institutional assessments, legislation, infrastructure, management, technologies and their applications.
\end{abstract}

Keywords: Distance education; Quality in distance education; CHD analysis; Similarity analysis.

\section{Resumen}

La educación a distancia en la educación superior ha crecido en Brasil, para algunos es una modalidad y para otros una nueva pedagogía con un nuevo campo de estudio, especialmente en la educación de adultos. Este impulso de la educación a distancia está marcado por el crecimiento tanto en instituciones como en estudiantes a través de la 
expansión de cursos y centros de apoyo, democratizando la enseñanza. Así, un aspecto que ha sido discutido en el EAD es la calidad, los estudios muestran que existe equivalencia en la calidad entre la enseñanza en el aula y a distancia al considerar los grados de las evaluaciones para la educación superior. El objetivo de este estudio fue identificar qué factores están relacionados con la calidad en la educación a distancia. Se realizó un análisis bibliográfico siguiendo procedimientos de selección en cuanto a citación y análisis de expertos para listar los artículos a evaluar. Luego de este filtro, se seleccionó la conclusión de estos artículos y se aplicó el análisis de contenido mediante el uso del software Iramuteq. Los resultados indican que la calidad es un concepto polisémico y está relacionado con la gestión, el compromiso del personal, el profesorado, los estudiantes, las evaluaciones institucionales, la legislación, la infraestructura, la gestión, las tecnologías y sus aplicaciones.

Palabras clave: Educación a distancia; Calidad en la educación a distancia; Análisis de CHD; Análisis de similitud.

\section{Introdução}

É irrefutável o uso do computador no processo de ensino e aprendizagem, o ensino a distância (EAD) tem que ser vislumbrado como uma nova pedagogia direcionada para adultos (Gadotti, 2010).

Há também uma reflexão quando se trata do olhar da educação como um mercado de oferta e demanda (Hermida \& Bonfim, 2006). Por outro lado, quando esta orientação tem como objeto a medição da qualidade por meio dos indicadores do ensino superior, tem-se que há uma equivalência entre o ensino presencial e a distância (Bielschowsky, 2018, p. 24). Isto demonstra a maturidade do Ensino a Distância, quanto aprendizagem e cultura.

Com o crescimento da educação a distância (EAD) tanto em instituições quanto em estudantes, na ordem de $45 \%$ a partir de 2000, despertou a discussão e desafio da qualidade para o EAD, quando analisado os indicadores de avaliação para o ensino superior, equipara-se as notas entre o ensino presencial e ensino a distância (Bielschowsky, 2018).

Não se trata de travar uma disputa entre ensino presencial e a distância, mas deve-se observar as oportunidades que a tecnologia da informação e comunicação (TICs) proporciona ao ambiente de ensino e aprendizagem. Belloni (2005) propõe um novo foco, substituindo o pensar em modalidade para a importância da pesquisa e metodologia ativa. Sendo assim, o EAD é algo sistêmico e não partes de uma tecnologia.

Por outro lado, destaca-se a inquietação de uma reprodução de educação baseada na quantidade e não na qualidade, conforme observa-se em Giolo (2010) que pontua os riscos na formação de professores, no sentido da longevidade dos reflexos desta. Ressalta-se a preocupação quanto ao mercado da educação, pensado em oferta e demanda que se sustenta na premissa de modernização (Hermida \& Bonfim, 2006, p. 179).

Uma proposta para um novo olhar encontra-se respaldo em Romiszowski (2008), com a finalidade de que o EAD seja observado como uma nova oportunidade e que erros e acertos fazem parte do processo, mas que não deve ser analisado para formar juízo de valor, pois este foco conduz a uma resistência que nada acrescenta para a aprendizagem.

A efetividade destas oportunidades possui relacionamentos internos e externos. Quanto aos liames internos, o ensino a distância é uma cultura que deve ser disseminada para toda a equipe, onde sua efetividade estaria relacionada a este nível de engajamento (D. Mill \& Dias, 2009, p. 9). No âmbito externo o sucesso do EAD estaria atrelado as políticas públicas (Chaves \& Duarte, 2019).

Tanto as políticas públicas quanto a cultura interna, quando fortalecidos pela democracia contribui para a qualidade do ensino, as medições são guias que ajudam no aperfeiçoamento do EAD, deve-se sempre buscar o diálogo com métricas robustas (Romiszowski, 2012).

Neste contexto, a qualidade está relacionada a formação, cultura EAD, treinamento, comunicação tanto interna quanto externa, formação dos profissionais que atuam com EAD, políticas públicas, ampliação de acesso à educação superior, perfil do aluno, perfil dos profissionais, gestão e TICs.

O resultado desta qualidade possui diferentes narrativas. Do ponto de vista da formação de professores é por alguns autores colocado em perspectiva, no sentido de que a formação de professores poderia refletir aspectos de baixa qualidade 
impactando em formações futuras, fazendo um paralelo com o Titanic (Giolo, 2010). Tal narrativa não se sustenta quando é realizada uma comparação de indicadores entre ensino presencial e a distância (Bielschowsky, 2018).

Dado estes aspectos, o que seria qualidade para os autores da educação? O objetivo deste estudo foi identificar os fatores de qualidade na educação a distância.

Foi utilizado a análise bibliográfica por meio de critérios de seleção quanto a citação, revista, congresso e análise por dois especialistas, um com Mestrado em Educação e outro com Doutorado na mesma área. Foram selecionados 34 artigos, e extraída a conclusão ou texto discursivo para obter os segmentos de textos por meio do uso do Software Iramuteq, separando as análises CHD e por similitude. Os resultados apontam que a qualidade é um conceito polissêmico que se relacionada com a gestão, engajamento da equipe, corpo docente, corpo discente, avaliações institucionais, legislação, infraestrutura, aprendizagem e aplicação das ferramentas de tecnologia da informação.

\section{Metodologia}

Para este estudo foram consultados artigos com o termo "Qualidade na educação a distância", tanto no título como nas palavras chaves nas bases Science Direct e Google Acadêmico. A pesquisa retornou mais de 1.000 (mil) referências, entre artigos, livros, teses, textos, documentos e dissertações. $\mathrm{O}$ foco deste trabalho foram os artigos, devido a qualidade objetiva dos periódicos e congressos.

Para selecionar um conjunto de artigos, como primeiro passo utilizou-se a quantidade de citações dos artigos, filtrando em até 5 citações e posteriormente uma análise da revista e do congresso que são métricas que podem ser aplicadas como critério de qualificação (Conforto, Amaral, \& Silva, 2011).

Regressou 200 artigos. Para filtrar estes artigos utilizou-se a análise de especialistas empregada para identificar as entradas dos artigos (Conforto et al., 2011). Os artigos foram avaliados por dois especialistas na área de educação, um com Mestrado e outro com Doutorado em Educação. Em seguida, selecionou-se 38 artigos dos quais 4 foram eliminados por questões de métricas de qualidade dos periódicos.

Após a seleção de artigos, foram extraídas a conclusão ou o texto com a defesa da argumentação proposta pelos autores, a fim de identificar suas conclusões frente aos objetivos traçados. Posteriormente seguiu-se o roteiro da análise de conteúdo por meio do Software Iramueq, separando as análises CHD e similitude. A primeira identifica o agrupamento das palavras para determinar um sentido para a classe, calculando no agrupamento os segmentos de textos, participação e o quiquadrado (X2) avaliando a significância e distância das variáveis. A análise de similitude, identifica os nós e a relação entre eles, quanto menor a distância maior a proximidade. Outros estudos também utilizaram este software e procedimentos para delinear seus resultados (Klant \& Santos, 2021; Schraiber, Melo, \& Urpia, 2021).

\section{Resultados e Discussão}

O corpus geral foi constituído por trinta e quatro textos, separados em 535 segmentos de texto (ST), com aproveitamento de 488 (91,21\%). Emergiram 18.991 ocorrências (palavras, formas ou vocábulos), sendo 2.559 palavras distintas e 16.392 com uma única ocorrência. O conteúdo analisado foi categorizado em 6 categorias: Classe 1, com 116 ST (23,77\% do total); Classe 2, com 32 ST (6,56\% do total); Classe 3 com 115 ST (23,57\% do total); Classe 4 com 36 ST (7,38\% do total); Classe 5 com 93 ST (19,06\% do total) e Classe 6 com 96 ST (19,67\% do total). Para efeitos deste estudo considera-se estatisticamente relevante as classes que possuem $\mathrm{x}^{2}>3,84$ e índice de significância $\mathrm{P}<0,05$.

A classe 1 compreende 116 ST que representam $23,77 \%$ do total. Constituída por palavras e radicais no intervalo com $x^{2}=3,88$ (complexo) e 91,15 (aprendizagem). Foram eliminadas da análise as palavras com $p<0,05$, por não expressarem $95 \%$ de confiança. 
A classe 2 compreende 32 ST que representam 6,56\% do total. Constituída por palavras e radicais no intervalo com $\mathrm{x}^{2}=4,51$ (educador) e 57,47 (prol). Foram eliminadas da análise as palavras com $\mathrm{p}<0,05$, por não expressarem $95 \%$ de confiança.

A classe 3 representa 115 ST que representam 23,57\% do total. Constituída por palavras e radicais no intervalo com $\mathrm{x}^{2}=3,96$ (melhor) e 49,9 (Brasil). Foram eliminadas da análise as palavras com p<0,05, por não expressarem $95 \%$ de confiança.

A classe 4 compreende 36 ST que representam 7,38\% do total. Constituída por palavras e radicais no intervalo com $\mathrm{x}^{2}=3,94$ (país) e 70 (resultado). Foram eliminadas da análise as palavras com p<0,05, por não expressarem $95 \%$ de confiança.

A classe 5 compreende 93 ST que representam 19,06\% do total. Constituída por palavras e radicais no intervalo com $x^{2}=3,87$ (exigir) e 72,14 (comunicação). Foram eliminadas da análise as palavras com p<0,05, por não expressarem $95 \%$ de confiança.

A classe 6 compreende 96 ST que representam 19,67\% do total. Constituída por palavras e radicais no intervalo com $\mathrm{x}^{2}=4,22$ (academia) e 38,95 (político). Foram eliminadas da análise as palavras com $\mathrm{p}<0,05$, por não expressarem $95 \%$ de confiança.

A Figura 1, apresenta o dendrograma e a relação entre as classes, demonstrando dois subcorpus sendo A e B. O subcorpus A é formado pelas Classes 1 e 5, o subcorpus B é formado por três ramificações C, D e E, sendo a ramificação C representada pela Classe 6, a ramificação D pela classe 4 e a ramificação E pelas classes 3 e 2.

Figura 1: Dendograma das Classes.

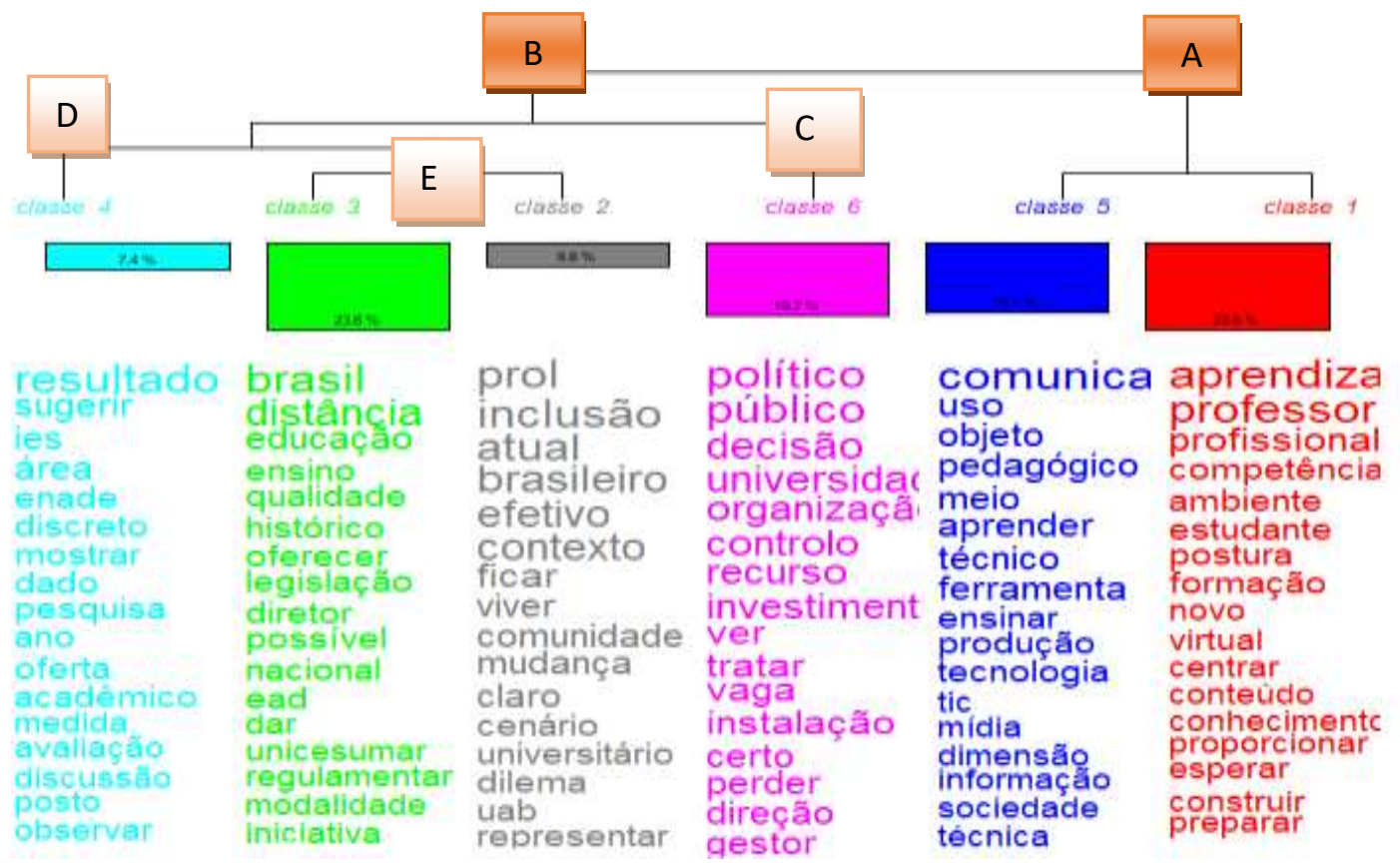

Fonte: Elaboração Própria (2021).

Conforme a Figura 1, as classes por se relacionarem em clusters, possuem características comuns no agrupamento. Na classe 1 pode-se denominá-la de aprendizagem, a classe 2 de inclusão, a classe 3 Instituições de Ensino, a classe 4 de avaliação, a classe 5 de tecnologia e a classe 6 de gestão.

Em aprendizagem alguns recortes do conteúdo relacionado a classe 1.

“...estudar a distância requer um novo tipo de estudante e um novo tipo de professor o estudante tem que saber o que quer e estar motivado para o curso escolhido" (Gadotti, 2010, p. 22) 
“...chamou se a atenção para a formação de professores a distância o titanic está chegando perigosamente próximo ao iceberg em boa hora o coro dos que alertam para o perigo está se ampliando e elevando o brado” (Giolo, 2010, p. 1292)

“...considerada a partir desta perspectiva mais ampla a EAD é apenas uma das modalidades possíveis de oferta de ensino e de formação profissional e o fundamento da educação deve ser a pesquisa com o objetivo de aprender a aprender" (Belloni, 2005, p. 190)

“...em segundo lugar é imprescindível levar em conta que o uso adequado das tic promove e exige uma abordagem interdisciplinar da educação pois requer que o professor domine o uso das ferramentas e trabalhe coletivamente com profissionais de diferentes áreas". Belloni, 2005, p. 193).

“....a criação de uma linguagem comum ao professor tutor e ao estudante no momento do processo de desconstrução reconstrução do conhecimento ainda significa um longo a se fazer no processo ensino aprendizagem" (Oliveira, Ferreira, \& Dias, 2004, p. 9)

“...elas têm auxiliado a compreensão de como proporcionar um ambiente de aprendizagem que seja mais condizente com o que o aluno vai encontrar ao longo da vida profissional" (Valente, 2019, p. 112).

“...se ele não puder ser ativo e mais autônomo no seu processo de aprendizagem certamente ele terá muita dificuldade de se manter atualizado na vida profissional” (Valente, 2019, p. 112).

Diante do exposto há uma preocupação com o perfil do professor e do estudante, o fator motivação é crucial para o processo de aprendizagem (Gadotti, 2010), é preciso romper paradigmas e estar disposto a aprender novas tecnologias, ser mais flexível as mudanças (Oliveira et al., 2004), que exigem uma visão mais sistêmica e estar inclinado a trabalhar com um universo tecnológico e com equipes multidisciplinares para que obtenha êxito na aprendizagem (Belloni, 2005), sendo assim o ensino a distância promove maior autonomia exigindo uma atitude mais ativa do estudante que de certa maneira está adequada ao mundo contemporâneo (Valente, 2019).

Porém há uma tensão relatada quanto a formação de professores no sentido da qualidade não atender a demanda da sociedade (Giolo, 2010), contudo para Bellioni (2005), trata-se apenas de mais uma modalidade de ensino. Diante do exposto, a aprendizagem no EAD por um lado está conexa ao domínio das ferramentas e integração da equipe e por outro a motivação do aluno onde se exige uma postura mais ativa.

Em inclusão, Classe 2, os recortes textuais foram:

“...a EAD não é só uma outra modalidade de ensino é também outro paradigma com outra pedagogia isso fica claro sobretudo quando se trata do estudante adulto o qual precisa ser mais autônomo e responsável pela sua formação (Gadotti, 2010, p. 23).

"há uma tendência de se achar que realizar análises para verificar o que é mais adequado para determinada realidade educacional implica num julgamento do mérito da plataforma tecnológica falta o entendimento de que em educação a distância (Romiszowski, 2008, p. 5).

“...nosso esforço é para que a educação a distância esteja bem concebida e enraizada em todos os departamentos e centros de ensino da instituição o desafio está na mudança de mentalidade de toda a comunidade universitária em prol de uma EAD efetiva" (D. Mill \& Dias, 2009, p. 9).

“...contudo independentemente dos números e do sucesso até aqui alcançados fica claro que o governo e a sociedade Brasileira ainda terão que enfrentar desafios mais pesados pela frente” (Eliot, 2009, p. 300).

“....a prática da avaliação na EAD deve ser guiada pela crença no valor da avaliação orientações teórico metodológicas pertinentes critérios de qualidade representativos da realidade negociação e diálogo" (Romiszowski, 2012, p. 9).

“...nas últimas décadas os números mostraram que o Brasil precisa investir e mudar de estratégia na área educacional objetivando atingir um maior número de pessoas” (Souza, Spanhol, Oliveira Limas, \& Pereira Casso, 2017, p. 10).

Diante disto, o EAD não pode ser visto como uma mera modalidade, mas como algo estruturado e planejado para atender a comunidade, trata-se de uma nova pedagogia e ao desvelar o estudante adulto, torna-se campo da aplicação da andragogia (Gadotti, 2010), deve-se buscar oportunidades e analisar os acertos e erros a fim de deputar as ferramentas e estratégias de aprendizagem. Portanto a resistência às tecnologias pode induzir a falta de conhecimento (Romiszowski, 2008, p. 5). 
É preciso uma mudança de mentalidade, o EAD tem um laço cultural, toda a equipe precisa mudar a forma de pensar para que o ensino seja efetivo (D. Mill \& Dias, 2009, p. 9).

A democracia no EAD contribui para a qualidade, as medições são guias que ajudam no aperfeiçoamento do ensino, deve-se sempre buscar o diálogo com métricas de medição robustas (Romiszowski, 2012). Sendo assim, o EAD promove uma maior amplitude na possibilidade de atingir mais pessoas e para isto precisa de mais investimentos (Souza et al., 2017, p. 10).

Não se trata de resistir às mudanças, mas aceitar que o EAD diz respeito a uma nova forma pedagógica a ser pensada e desenvolvida, deve ser estruturada e praticada por todos, a fim de atingir os objetivos da aprendizagem. A inclusão pode-se separar em três aspectos. O primeiro relacionado a mudança em si, não se inclui com uma postura de resistência, para incluir é preciso mudar a forma de pensar e agir. No outro aspecto trata das medições e aceitação das ferramentas a fim de depurar os erros e acertos com o propósito de melhoria do modelo, incluir neste sentido passa pelos critérios de qualidade e melhoria. Por fim, a oportunidade em ampliar o ensino, dando maior acessibilidade as pessoas de tal forma que este processo seja amplamente estruturado, discutido e dialogado.

Os recortes textuais em Instituições de Ensino, Classe 3, são:

“...concluímos reafirmando nosso entendimento que a educação superior a distância desempenha importante papel na educação superior do país já que a maior parcela das IES que oferecem EAD demonstra qualidade equivalente àquela do ensino presencial e pode ajudar a alavancar uma sociedade mais desenvolvida e justa" (Bielschowsky, 2018, p. 24). “.... implantação do programa universidade aberta do Brasil (UAD) impõe a todos nós um compromisso com a qualidade de ensino neste país e assim compreendemos que os problemas apresentados ao docente tutor virtual devem ser vistos como desafios a serem solucionados" (Daniel Mill, Abreu-e-Lima, Lima, \& Tancredi, 2008, p. 124).

"cursos de graduação formação inicial a distância o que fará a conferência nacional em 2010 com essa proposta o que fará o Brasil com esse dilema quaerenti propere danda est responsio lenta" (Giolo, 2010, p. 1292).

“...a universidade torna se um mero mercado de compra e venda cursos rápidos a longa distância tudo em função do que denominam de modernização da educação cabe repensar em que sentido ocorre essa modernização e a quem objetiva beneficiar" (Hermida \& Bonfim, 2006, p. 179).

"...transmitir a segurança necessária a todos que queiram oferta-la ou estejam envolvidos em processos dessa natureza alunos profissionais da área instituições de ensino e sociedade em geral" (Ferreira Lessa, 2011, p. 27).

Em Instituições de ensino (IEs), tem dois construtos. O primeiro diz respeito aos índices de qualidade, quando comparados entre Instituições de Ensino que oferecem EAD com as que não oferecem, observa-se que as notas são equivalentes (Bielschowsky, 2018). O outro apresenta-se do ponto de vista do Mercado, há um mercado para cursos EAD e este mercado está baseado em transações comerciais cuja argumentação centra-se na modernização da educação. De certa forma, a análise dos dois construtos se mostra opostas, um pontuando que as evidências são de que a qualidade é equivalente e o outro de que o foco no mercado prejudica a qualidade. Nota-se que qualidade em Educação é um conceito polissêmico, pode estar relacionada ao corpo docente, infraestrutura, notas das avaliações promovidas pela administração pública, do ponto de vista do empregador e outros. É notório que somente a perspectiva do mercado não pode chancelar o que seria qualidade e tampouco somente as notas das avaliações do ensino superior. Pelo exposto, não é possível pensar em qualidade sem mercado, senão reduziria a capacidade de investimento destas instituições.

No que tange a Avaliação, Classe 4, os recortes foram:

“...consolida avanços metodológicos com resultados acadêmicos positivos nos cursos presenciais avançando para o que muitos de nós acreditamos que essas duas modalidades estarão cada vez mais próximas com o passar do tempo" (Bielschowsky, 2018, p. 23).

“...não conseguimos realizar uma análise equivalente para anos anteriores mas resultados aproximados mostram pequeno aumento da divergência entre os resultados dos cursos presenciais e de EAD já a partir de 2012" (Bielschowsky, 2018, p. 23). 
“....os dados do INEP ainda não são suficientemente completos e objetivos no que se refere à variável evasão, mas a conjectura de ser alta que responsabilidade as instituições terão nesse particular poderão operar com qualquer índice de evasão ou deverão ter um patamar máximo" (Bertrams, Baur, Grüneklee, \& Hintzen, 1980, p. 1231).

No aspecto temporal, em 1980 havia um foco de qualidade direcionada para evasão escolar (Bertrams et al., 1980), não tratava propriamente do ensino a distância. Já em 2012 as avaliações mostram uma aproximação de resultados comparando a modalidade presencial e a distância. Isto posto, o EAD vem desempenhando um foco em melhoria de ensino, aprendizagem, infraestrutura e outras.

Para a tecnologia, Classe 5, os recortes textuais são:

“...o computador é hoje mais do que qualquer coisa um meio de comunicação ele é a principal tecnologia educacional com a qual se ensina e se aprende com o computador eliminam se os intermediários na informação" (Gadotti, 2010, p. 22)

“...a da integração das tic nos processos educacionais como meio de democratizar o acesso a uma verdadeira formação emancipatória" (Belloni, 2005, p. 192)

“...constituindo se em um meio de nos aproximarmos da educação quando não a podemos realizar regularmente significa ainda recursos para obter informação e aprender autonomamente de acordo com os indicativos motivacionais e o ritmo de aprendizagem de cada um" (Oliveira et al., 2004, p. 9).

".... autora deste artigo entende que discutir qualidade da EAD sob o viés da avaliação favorece uma reflexão sobre vários aspectos que contribuem para a melhoria educacional se no passado a avaliação não cumpriu o seu papel é preciso aprender a fazê-la melhor com transparência ética e atitude científica" (Romiszowski, 2012, p. 9).

É axiomático que o computador mudou a forma com que se ensina e aprende, o acesso à informação é mais democrático e dispensa intermediários (Gadotti, 2010), isto impõe um novo pensar em termos de pratica pedagógica. Assim, tanto a tecnologia quanto a aprendizagem se posicionam no mesmo subcorpus, figura 1, isto sublinha a importância destes dois eixos para o EAD. A avaliação cumpre um papel importante para a tecnologia, os erros e acertos devem ser encarados a luz da ética e atitude científica para desvelar a realidade da qualidade do EAD (Romiszowski, 2012).

Em Gestão, Classe 6, considera-se:

“...obviamente os requisitos básicos para o desenvolvimento de cursos a distância nas instituições educacionais inovadoras devem incluir no modelo de negócio todos os subsistemas que interagem para que as estratégias pensadas sejam concretizadas com sucesso" (Araújo, Oliveira Neto, Cazarini, \& Oliveira, 2013, p. 650).

“...o programa de apoio a planos de reestruturação e expansão das universidades reuni que figura como a primeira etapa em processo de consolidação da expansão por exemplo prevê o investimento de mais de dois bilhões de reais entre os anos de 2008 e 2011" (Eliot, 2009, p. 300)

“...felizmente já podemos observar esforços públicos e privados no sentido de criar consórcios e promover um grande debate visando a organizar os pressupostos teóricos e práticos para avançar na estruturação de uma grande rede de EAD (Souza et al., 2017, p. 11).

“...falar em EAD em um país como o Brasil é observar a possibilidade de êxito nas diversas instâncias da prática educativa porém a efetivação de sucesso encontra se vinculada em grande parte às decisões pertencentes ao âmbito das políticas públicas" (Chaves \& Duarte, 2019, p. 10).

“...outros fatores que contribuíram no estabelecimento da educação a distância foi a criação de organizações instituições de ensino como as universidades abertas que faziam uso da modalidade e até mesmo as instituições que empregava o ensino tradicional" (Santos \& Menegassi, 2018, p. 226).

Em gestão, os investimentos em EAD somam-se na casa dos bilhões e deve haver um esforço tanto público quanto privado por meio de consórcios, avançando para grandes redes. O sucesso do EAD encontra amparo nas políticas públicas, porém não com exclusividade. Neste sentido, o EAD possui estratégias que tem como pressupostos a teoria, prática e ampliação por meio de investimentos maciços e políticas públicas bem delineadas.

$\mathrm{Na}$ análise de similitude no eixo central situa-se a Educação que diz respeito as universidades, ensino superior e sociedade. A educação está ligada ao ensino que conecta com aprendizagem que esta agrupada com processo envolvendo 
conhecimento, pedagógico, social e profissional. Também liga com EAD quanto modalidade, gestão, avaliação, trabalho, instituição, curso e por fim político. Ainda a educação está conexa com o novo que remete a maturação da tecnologia e seu uso. E por fim em uma intersecção com ensino a distância encontra-se a qualidade, que diz respeito ao professor, aluno, didático, diferente e ramificando para os demais eixos. A Figura 2, apresenta a análise de similitude.

Figura 2: Análise de similitude.

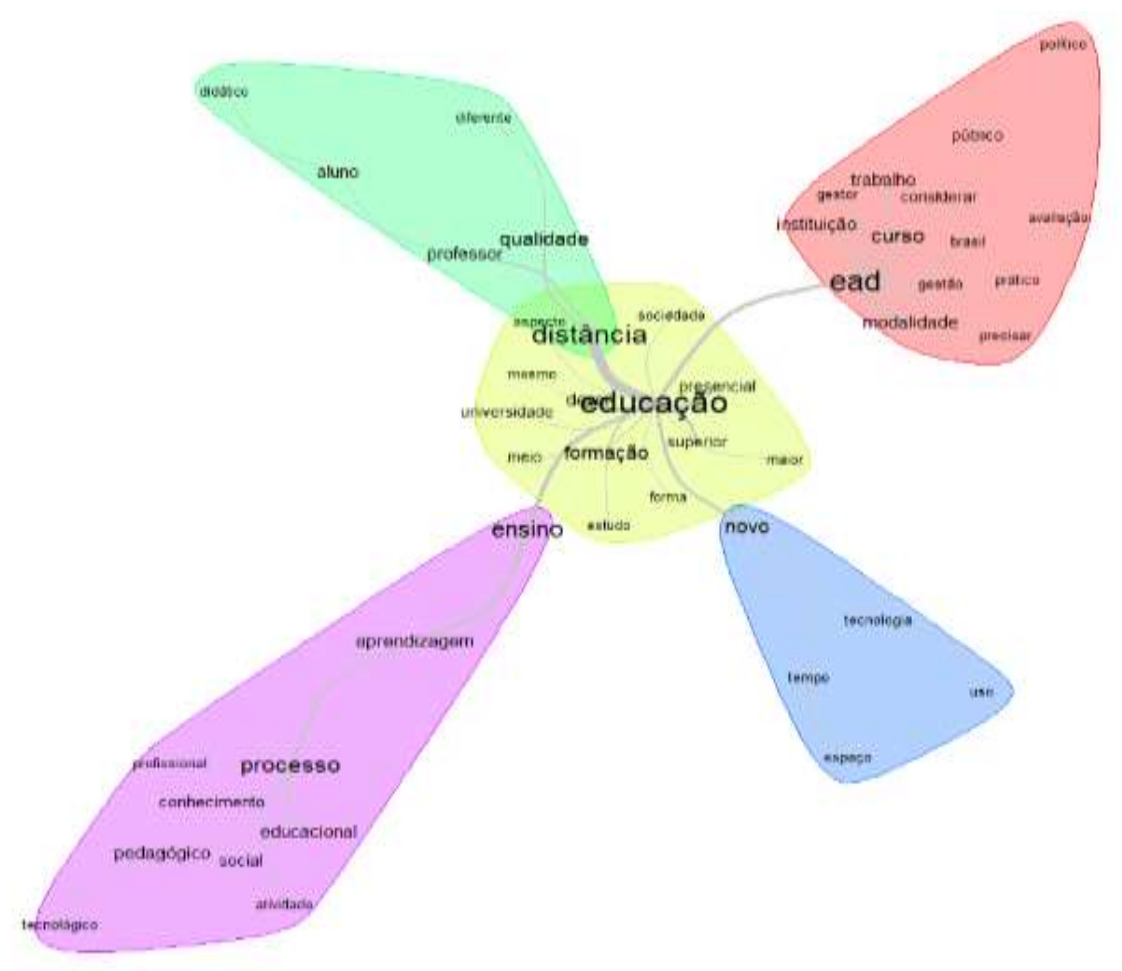

Fonte: Elaboração Própria (2021).

\section{Conclusão}

Neste estudo os fatores foram distribuídos em dois subcorpus, sendo de um lado a tecnologia e aprendizagem e do outro estão a gestão, inclusão, instituições de ensino e avaliação.

A qualidade na Educação a distância é marcada por fatores múltiplos, referindo-se à formação dos profissionais, o processo de aprendizagem quanto aos meios pedagógicos adotados, o conhecimento das TICs e sua aplicação, a facilidade de comunicação tanto da equipe quanto dos estudantes, a aceitação do novo por toda a comunidade, o processo de gestão como estratégia para o crescimento, aumento de investimentos, inclusão das pessoas por meio da ampliação da oferta de cursos e polos de apoio presencial.

Estes fatores desvelam a complexidade do ensino a distância para atingir os objetivos da qualidade, que podem ser melhorados ao longo do tempo, como demonstram os indicadores das avaliações tanto institucionais quanto de curso.

Trabalhar estes fatores em um modelo de qualidade institucional de maneira democrática, com transparência, ética e métricas fortalece a qualidade para o EAD.

Para estudos futuros recomenda-se que seja realizado estudos de caso estabelecendo métricas de qualidade para os fatores, a fim de criar ou melhorar modelos existentes de avaliação que não foquem somente em aspecto de infraestrutura, corpo docente ou avaliações de estudantes, mas consiga indicar um caminho de análise longeva e inclusiva. 


\section{Referências}

Araújo, E. M. de, Oliveira Neto, J. D. de, Cazarini, E. W., \& Oliveira, S. R. M. (2013). A gestão da inovação na educação a distância TT - Innovation management in distance education. Gestão \&amp; Produção, 20(3), 639-651. http://www.scielo.br/scielo.php?script=sci_arttext\&pid=S0104530X2013000300010\&lang=pt\%0Ahttp://www.scielo.br/pdf/gp/v20n3/v20n3a10.pdf

Belloni, M. L. (2005). Educacão a distância e inovacão tecnológica. Trabalho, Educação e Saúde, 3(1), 187-198. https://doi.org/10.1590/s198177462005000100010

Bertrams, J., Baur, M. P., Grüneklee, D., \& Hintzen, U. (1980). Association of Bf F1 and Haplotype HLA-B18, Bf F1 with Insulin-Dependent Diabetes Mellitus. Immunobiology, 158(1-2), 129-133. https://doi.org/10.1016/S0171-2985(80)80052-0

Bielschowsky, C. E. (2018). Qualidade na Educação Superior a Distância no Brasil: Onde Estamos, para Onde Vamos? EaD Em Foco, 8(1), 1-26. https://doi.org/10.18264/eadf.v8i1.709

Chaves, D. de A., \& Duarte, S. L. O. (2019). Reflexão Sobre O Contexto Da Educação a Distância E a Importância Da Ação Do Designer Instrucional No Ambiente Virtual De Aprendizagem. Congresso Internacional de Educação e Tecnologias: Experiências, Desafios e Perspectivas 2, 177-189. https://doi.org/10.22533/at.ed.75319180418

Eliot, C. W. (2009). A Educação a Distância como Política de Expansão e Interiorização da Educação Superior no Brasil. Revista de Ciências Da Administração, 11(24), 278-304.

Ferreira Lessa, S. C. (2011). Os reflexos da legislação de educação a distância no Brasil. Revista Brasileira de Aprendizagem Aberta e a Distância, 10. https://doi.org/10.17143/rbaad.v10i0.230

Gadotti, M. (2010). Qualidade na educação: uma nova abordagem. Centro de Referência Paulo Freire, 1-25.

Giolo, J. (2010). Educação a Distância: Tensões entre o público e o priavado. Educ. Soc., 31(113), 1271-1298.

Hermida, J. F., \& Bonfim, C. R. de S. (2006). a Educação À Distância: História, Concepções E Perspectivas. Revista HISTEDBR Online, 44(1995), 114-130. Mill, D., \& Dias, N. (2009). Gestão Da Educação A Distância: Origens e Desafios. Congresso ABED, 4(May), 1-10. http://www2.abed.org.br/congresso2009/CD/trabalhos/652009145737.pdf

Mill, Daniel, Abreu-e-Lima, D., Lima, V. S., \& Tancredi, R. M. S. P. (2008). O desafio de uma interação de qualidade na educação a distância: o tutor e sua importância nesse processo. Cadernos Da Pedagogia, 02(04), 112-127. http://www.cadernosdapedagogia.ufscar.br/index.php/cp/article/view/106/63

Oliveira, E. da S. G. de, Ferreira, A. C. da R., \& Dias, A. C. S. (2004). Tutoria Em Educação a Distância: Avaliação E Compromisso Com a Qualidade. 11 Congresso Internacional ABED de Educação a Distância, 1-10.

Romiszowski, H. P. (2008). Avaliação no Design Instrucional e Qualidade da Educação a Distância: qual a relação? Revista Brasileira de Aprendizagem Aberta e a Distância, 3, 1-7. https://doi.org/10.17143/rbaad.v3i0.159

Romiszowski, H. P. (2012). Qualidade na educação a distância. Ufsc, 1-10. http://repositorio.ufsc.br/handle/123456789/86754

Santos, L. C. dos, \& Menegassi, C. H. M. (2018). A história e a expansão da educação a distância: um estudo de caso da UNICESUMAR. Revista Gestão Universitária Na América Latina - GUAL, 11(1), 208-228. https://doi.org/10.5007/1983-4535.2018v11n1p208

Souza, C. A., Spanhol, F. J., Oliveira Limas, J. C., \& Pereira Casso, M. (2017). Tutoria Como Espaço De Interação Em Educação a Distância. Revista Diálogo Educacional, 4(13), 79. https://doi.org/10.7213/rde.v4i13.7028

Valente, J. A. (2019). Tecnologias E Educação a Distância No Ensino Superior. Trabalho \& Educação, 28(1), 97-113. https://doi.org/10.35699/2238$037 \times .2019 .9871$ 